\title{
Two-stage prognosis of postoperative complications in patients with acute peritonitis
}

\author{
A.F. GRYNCHUK, I.IU. POLIANSKIY, F.V. GRYNCHUK, P.V. MOROZ \\ Department of Surgery №1, Higher State Educational Establishment "Bukovinian State Medical \\ University", Ukraine
}

\begin{abstract}
Introduction. Acute peritonitis still remains one of the most severe and threatening abdominal cavity disease. An important component of the treatment of acute peritonitis is the ability to prognose adequately the possibility of postoperative complications, which allows to use appropriate preventive measures. For the case, numerous methods, based on the account of various parameters, are developed. But none of them is fully accepted, and useful.

Purpose. To develop an informative scale for postoperative complications predicting.

Material and method. The retrospective analysis of outcome of treatment of 169 patients with acute surgical pathology of abdominal organs complicated by various forms of peritonitis, 79 of whom developed postoperative complications results are presented. The dependence of occurrence and severity of complications on the nature of the underlying disease, clinical manifestations of peritonitis before surgery, anthropometric data research, laboratory methods, Mannheim peritonitis index parameters, comorbidity class, age were studied, using the analysis of variance.

Results. A scale according to which the prediction of complications is conducted in two stages, was developed. Before the surgery, we estimate the previous risk according to the nature of the underlying disease, clinical manifestations of peritonitis, comorbidity class. According to identified changes, the finalestimation due to the nature of the underlying disease, Mannheim peritonitis index parameters, comorbidity class, stab neutrophil leukocytes number, use of programmedperitoneal cavity sanations is being made during the operation. These indicators provided a certain number of points. Due to this points, patients were referred to several groups: normal group (less than 18), increased (18-25), medium (26-34) and high (more than 35) the risk of complications.

Conclusions. The developed scale makes it possible to apply the necessary preventive measures at all stages of treatment, since preoperative preparation.
\end{abstract}

Keywords: acute peritonitis, postoperative complications, prognosis

\section{INTRODUCTION}

An important component of the treatment of acute peritonitis is the ability to prognose adequately the possibility of postoperative complications, which allows to use appropriate preventive measures $(1,2,3)$. For the case, mentioned above, numerous methods, based on the account of various parameters $(4,5,6,7)$, are developed. But none of them is fully accepted, due to several reasons, including a large number of parameters that determine the complexity of use, low informative methods based on a small number of criteria etc. As a result, APACHE, SAPS, SOFA and other scales 
$(8,9)$ which allow to estimate the severity of the patients and possibility of death are suggested for predicting the effects of treatment. Mannheim peritonitis index (MPI) (5) is acknowledged in many countries, but its only function is determination of the peritonitis severity. It is clear, that with the increasing of peritonitis severity and the patients condition, the probability of postoperative complications increases, but mentioned above methods do not allow to differentiate the risk of separate postoperative complications. We should notice that the vast majority of prognostic scales allow to determine postoperative complications risk only after the operation. This reasons limit the applicability of preventive measures during the preoperative preparation. So the question of informative prognostic scale development is important, so the aim of the study is to develop an informative scale for postoperative complications predicting .

\section{MATERIAL AND METHOD}

The retrospective analysis of the of 169 patients with acute surgical pathology, complicated by various forms of peritonitis, aged 17 to 84 years treatment consequences was conducted. Male 98 , female -71 were chosen. There were 51 cases of acute appendicitis, 26 - acute intestinal obstruction (non malignant), 23 - gastroduodenal ulcer perforations, 16 - incarcerated hernia, 13 acute cholecystitis and colon cancer, complicated by intestinal obstruction, 4 - obstetrical and gynecological pathology, 3 - perforation and injuries of the small intestine, 2 - acute pancreatitis and postoperative peritonitis and 2 cases of other diseases among them. 45 patients were diagnosed with local peritonitis 53 - with diffuse, 57 with poured, 13 with total. 79 patients had postoperative complications, including 24 cases of inflammation and wound suppuration, 5 - eventerations, 14 - intra-abdominal abscesses and infiltrates, 18 - of intestinal suture failure, 18 - continuous peritonitis. Death occurred within 39 patients. 123 patients were diagnosed with comorbidities.

The clinical and anthropometric data, laboratory methods, MPI parameters, comorbidity class (CC) (7), age were analysed. The factor impact was studied, using the variance analysis. The Clinical manifestations of peritonitis before the operations were evaluated in points: local peritonitis 2 , diffuse -4 , diffuse or total -6 points. To create the possibility of mathematical presence and severity of complications processing was evaluated as follows: 0 - no POC, 1 -inflammatory wound complications 2 - wound suppuration and eventration, 3 - bordered intra-abdominal complications, 4 - suture leakage and diffuse peritonitis, 5 - total peritonitis with systemic complications, that lead to death. Numerical characteristics of surgical diseases were conferred according to the univariate variance analysis results.

\section{STUDY RESULTS}

A scale, under which POC forecasting was carried out in two stages, was developed by us. In the first phase, before the operation, the scale included the following parameters: the nature of the underlying disease and peritonitis, parameters of the comorbidity class (Table 1). The results of variance analysis (Table 2 ) confirmed the statistically significant dependence of the POC from the indicators that were selected for prediction. It is significant, that the involvement of the indicators analysis which are widely used to predict (age, leukocyte count, urea, creatinine etc.) $(1,4)$, no statistically significant dependence of POC parameters dispersion on the complex of the determined factors was found. This caused the usage opportunity of the factors, just listed in table 1.

TABLE 1. A scale for postoperative septic complications of acute peritonitis predicting

\begin{tabular}{|l|c|}
\hline Criteria & Points \\
\hline $\begin{array}{l}\text { Acute appendicitis, acute cholecystitis simple, } \\
\text { gynecological pathology, intestinal obstruction } \\
\text { (non-tumor) without necrosis }\end{array}$ & $\mathbf{1}$ \\
\hline $\begin{array}{l}\text { Intestinal obstruction (non-tumor) with } \\
\text { necrosis, acute destructive cholecystitis, } \\
\text { perforation of gastroduodenal ulcers, small } \\
\text { intestine, stomach cancer, acute peptic ulcer } \\
\text { bleeding, obstetrical pathology }\end{array}$ & $\mathbf{2}$ \\
\hline $\begin{array}{l}\text { Abdominal trauma, tumor obstruction of the } \\
\text { colon, Crohn's disease, acute pancreatitis, } \\
\text { mesenteric thrombosis, postoperative } \\
\text { peritonitis }\end{array}$ & $\mathbf{3}$ \\
\hline Local peritonitis & $\mathbf{2}$ \\
\hline Diffuse peritonitis & $\mathbf{4}$ \\
\hline Total peritonitis & $\mathbf{6}$ \\
\hline No class & $\mathbf{0}$ \\
\hline Comorbidity class 0 & $\mathbf{0}$ \\
\hline Comorbidity class 1 & $\mathbf{1}$ \\
\hline Comorbidity class 2 & $\mathbf{2}$ \\
\hline Comorbidity class 3 & $\mathbf{3}$ \\
\hline
\end{tabular}

According to the amount of points, determined according to the scale, patients previously divided into several groups: normal (2-4 points), increased (5-7 points), medium (8-9 points) and high (more than 10 points) POC risk (Fig. 1). Such allocation of risk groups allows to use the necessary POC pre- 
TABLE 2. Results of the impact of certain factors on the development of postoperative complications in studied patients variance analysis

\begin{tabular}{|l|c|c|c|c|c|}
\hline Source & Sum of Squares & Df & Mean Square & F-Ratio & P-Value \\
\hline CC & 27.38 & 3 & 9.14 & 4.79 & 0.003 \\
\hline Peritonitis & 18.31 & 2 & 9.16 & 4.81 & 0.009 \\
\hline Main diagnosis & 69.73 & 18 & 3.87 & 2.03 & 0.011 \\
\hline Residual & 76.14 & 45 & 1.90 & - & - \\
\hline Total (corrected) & 497.76 & 168 & - & - & - \\
\hline
\end{tabular}

vention measures at the stage of preoperative preparation.

The final risk determination is made, based on the data of intraoperative revision and laboratory tests. The clinical and laboratory parameters analysis showed that POC parameters dispersion is statistically significantly explained by the insertion of the data, presented in Table 3. Based on the conducted analysis, a specified scale is created for the second phase prediction (Table 4).The programmed peritoneal cavity sanation indicators were extra included, as the repeated surgery increases the POC risk (3).

Risk groups differentiation is conducted as follows: less than 18 points - normal, 18-25 points increased (primarily wound complications), 26-34 points - average (abscesses, infiltrates, diffuse peritonitis, suture failure), more than 35 points -

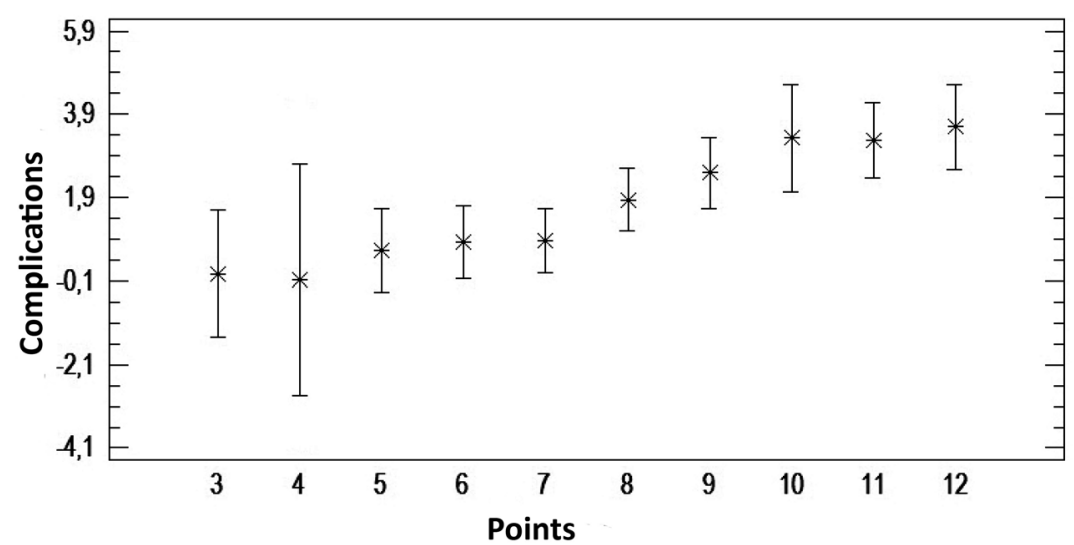

FIGURE 1. Means and 95.0 Percent Scheffe Intervals

TABLE 3. Results ofthe impact of certain factors on the development of postoperative complications in studied patients variance analysis

\begin{tabular}{|l|c|c|c|c|c|}
\hline Source & Sum of Squares & Df & Mean Square & F-Ratio & P-Value \\
\hline CC & 27.06 & 3 & 9.09 & 8.00 & 0.0001 \\
\hline Peritonitis & 91.96 & 28 & 3.28 & 2.91 & 0.000 \\
\hline Stab neutrophils & 86.69 & 2 & 38.46 & 38.46 & 0.000 \\
\hline Main diagnosis & 4.24 & 2 & 1.88 & 1.88 & 0.156 \\
\hline Residual & 49.87 & 33 & 1.12 & - & - \\
\hline Total (corrected) & 497.76 & 168 & - & - & - \\
\hline
\end{tabular}

TABLE 4. A scale for preoperative complications predicting

\begin{tabular}{|l|l|}
\hline Criteria & Points \\
\hline Characteristics of surgical pathology & Due to table 1 \\
\hline Characteristics peritonitis & MPI \\
\hline Characteristics of the concominent disease & Due to table 1 \\
\hline Content of the stab neutrophils (\%) & \\
less than 3 or more than 37 & $\mathbf{3}$ \\
26-36 & $\mathbf{2}$ \\
4-25 & $\mathbf{0}$ \\
\hline The use of programmed sanation & $\mathbf{2}$ \\
\hline
\end{tabular}




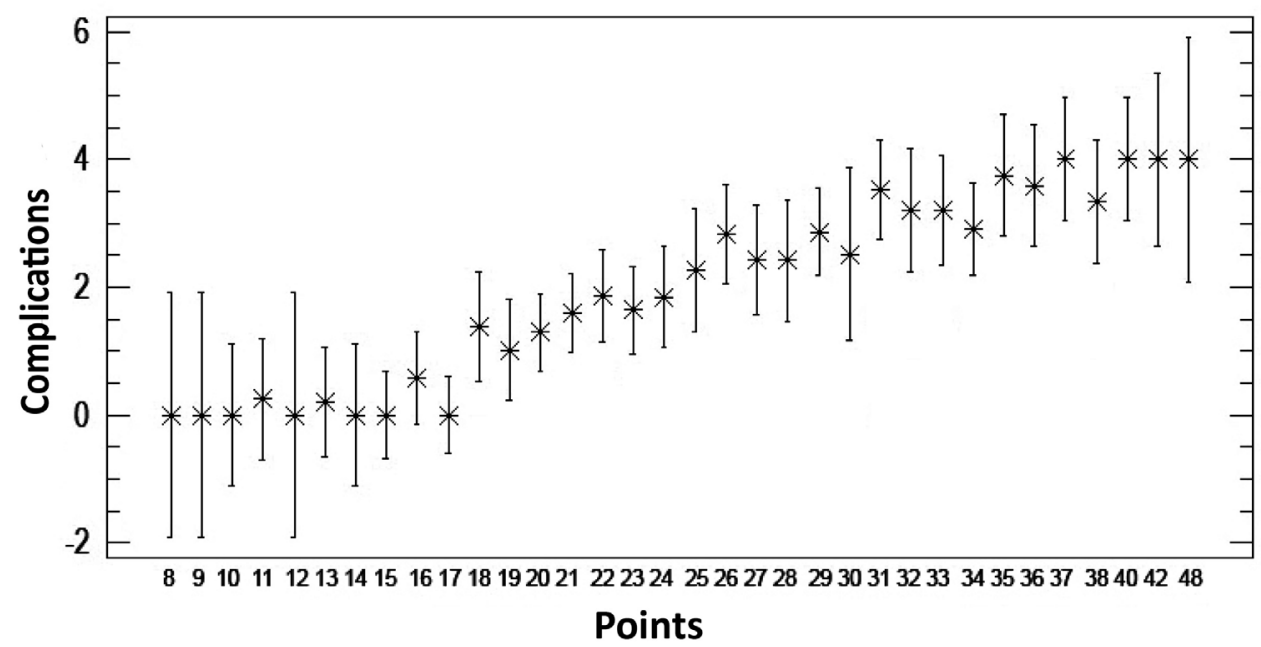

FIGURE 2. Means and 95.0 Percent Scheffe Intervals

high risk (severe peritonitis, sepsis), what was confirmed by the results of the univariate variance analysis (Fig. 2). The allocation of a particular patient to a specific group allows to use reasonably necessary preventive measures during surgery and in the postoperative period.

\section{CONCLUSIONS}

1. The proposed prognostic scale allows to allocate reasonably groups of normal, increased, me- dium and high risk of postoperative complications at acute peritonitis.

2. Conducting the prediction in two phases before and during surgery, can differentially apply preventive measures in the course of preoperative preparation, during the operation and in the postoperative period treatment.

Prospects for further research. Further research should be directed at reasonable postoperative complications preventing methods development.

\section{Conflict of interest: none declared} Financial support: none declared

\section{REFERENCES}

1. Andryushchenko VP, Fedorenko ST, Andryushchenko DV. Hostryy hniynyy poshyrenyy perytonit: providni komponenty suchasnoyi khirurhichnoyi taktyky. Klin anat ta oper khirurh. 2012;11(2):91-3. (in Ukrainian).

2. Kryvoruchko IA, Antonova MS. Ranni ta pizni uskladnennia pry likuvanni khvorykh na abdominalnyi sepsys (Early and late complications in the treatment of patients with abdominal sepsis). Kharkiv khirurh shkola. 2016;2:56-60. (In Ukrainian).

3. Polianskyi Ilu, Hrynchuk FV, Andriiets VV, Maksym'iuk VV, Brodovskyi VV, Voitiv Yalu. Klasyfikatsiia hostroho perytonitu
(Classification of acute peritonitis). Klin anat ta oper khirurh. 2012;11(2):68-70. (In Ukrainian).

4. Germer CT, Eckmann C. Peritonitis. Der Chirurg. 2016;87(1):3-4. doi: 10.1007/ s00104-015-0118-5.

5. Baba Guru Prasad N, Bhaskar Reddy KV. A study of acute peritonitis: evaluation of its mortality and morbidity Int Surg J. 2016;3(2):663-668. DOI: 10.18203/23492902.isj 20161140

6. van Ruler OM, Boermeester A. Surgical treatment of secondary peritonitis $A$ continuing problem. Der Chirurg. 2017;88(1):1-6.
7. Grynchuk FV. Nova shkala dlia otsiniuvannia komorbidnosti v nevidkladnii abdominalnii khirurhii (New scale for assessing comorbidity in emergency abdominal surgery). Art of Medicine. 2018;4(8):55-7. (In Ukrainian).

8. Grynchuk AF. Kompleksna diahnostyka i prohnozuvann perebihu hostroho perytonitu. Art of Medicine. 2018;4(8):5255.

9. Linder MM, Washa H, Feldmann U. Der Mannheimer Peritonitis-Index. Chirurg. 1987;58(2):84-92. 